\title{
Retenções de silêncio no entremear de vozes: notas polifônicas na escrita antuniana
}

\author{
Tatiana Prevedello ${ }^{1}$
}

\begin{abstract}
RESUMO: As obras Eu hei-de amar uma pedra e Boa tarde às coisas aqui embaixo, de António Lobo Antunes, ao enredarem impressões memorialistas, situações existenciais e fatos históricos de personagens reclusas em calabouços de silêncio e solidão possibilitam, com base nos pressupostos teóricos de Bakhtin, uma análise dos recursos polifônicos que se entrelaçam à tessitura narrativa.
\end{abstract}

ABSTRACT: The works Eu hei-de amar uma pedra and Boa tarde às coisas aqui embaixo, by António Lobo Antunes, entangling memorial impressions, existential situations and historical events about characters recluse in dungeon of silence and solitude, based in Bakhtin's theoretical presupposed, enable an analysis of the polyphonic resources that intertwine the narrative fabric.

PALAVRAS-CHAVE: Silêncio; Memória; Polifonia; Lobo Antunes; Bakhtin KEYWORDS: Silence; Memory; Polyphony; Lobo Antunes; Bakhtin

\section{"Pensa, completamente silencioso": umas, primeiras, palavras}

A produção literária de Lobo Antunes demonstra um distanciamento do conceito clássico de narração, por convocar uma suposta desconstrução genealógica, em relação ao cânone literário. Na escrita antuniana imprime-se a tendência para a reconversão dos gêneros literários, a qual pode estar a refletir uma contingência histórico-cultural e ideológica, possibilitada pelo Portugal do século XX. $\mathrm{Na}$ atmosfera portuguesa contemporânea, na qual se insere a prosa de Lobo Antunes, imprime-se um profundo estigma pós-revolucionário, cujas cicatrizes revelam um intenso mal-estar social e civilizacional. Nessa perspectiva, a nação portuguesa, projetada no olhar do escritor,

1 Doutoranda em Literaturas e Culturas Românicas. Faculdade de Letras da Universidade do Porto (FLUP). Pesquisa: "Da expressão do tempo ao estilhaçamento do eu: figurações da memória em Lobo Antunes". Contato: t_prevedello@hotmail.com 
está a convocar, desde sua estreia na literatura, em 1979, a aflição de um mundo sem sentido, de fronteiras fisicas e mentais desumanizadas.

Os textos ficcionais de Lobo Antunes exploram um dos aspectos mais angustiantes que emergiram com a contemporaneidade, no que se refere à consciência de que inexiste uma realidade única, ou uma verdade absoluta, elementos que se tornam evidentes pela crise da história, questionada por seu olhar artístico. Uma avaliação dessa natureza possibilita um redimensionamento à ficção, uma vez que, ao desvincular-se de um compromisso com a realidade, e por não ter pretensões científicas, traz na liberdade de expressão vigente em seu universo, as múltiplas realidades sentidas e vividas pelo homem.

Nesse plano, instauram-se as obras Boa tarde às coisas aqui embaixo e Eu hei-de amar uma pedra, as quais são elaboradas a partir de fragmentos de histórias que se apresentam aparentemente destituidas de um fio condutor, de personagens reclusas em margens de silêncios e desligadas do enquadramento social. O olhar narrativo, então, expressa a sua perplexidade diante da vida por meio de alteridades estilhaçadas, universos fragmentados e na própria fuga da cena literária convencional.

O narrador, e a maioria das personagens de ambas as obras, atuam em um mundo desumanizado, em uma sociedade e em uma época nitidamente marcadas por sentimentos que dificultam e limitam os relacionamentos, mergulhados em um autismo atroador e de frustração profunda. O texto antuniano desafia o leitor a empreender esforços na tentativa de agrupar os fragmentos textuais e, com esse material, participar no desenvolvimento da representação narrativa da memória, a fim de constituí-la como parte integrante da ficção, reconhecendo, ao mesmo tempo, aquilo que nesse conteúdo existe de profundamente humano e paradoxal.

As narrativas Eu hei-de amar uma pedra e Boa tarde às coisas aqui embaixo se colocam em um plano plural, ambivalente, pois a partir de existências submersas em repreensões silenciosas, é instaurada a possibilidade de se oferecer voz às diferenciadas realidades. Afirma-se 
que o texto adquire a forma de um objeto social (BARTHES, 2004, p. 267-268), do qual o intelectual dispõe para problematizar questões inerentes à humanidade. Formular respostas ou soluções para tais questões, portanto, não é permitido. Neste enquadramento de texto estão situadas as obras supracitadas, ao apresentar, fragmentadamente, o indivíduo deslocado no universo pós-colonial português e no seu próprio espaço interior.

Ambos os textos configuram-se como narrativas polifônicas, as quais veiculam em seu discurso a flagelação humana e as suas íntimas peculiaridades, revelando um universo de degradação e ruínas morais, tanto do indivíduo frente às suas angústias existenciais como do império colonial português e do sistema angolano pós-colonialismo. As narrativas Eu hei-de amar uma pedra e Boa tarde às coisas aqui embaixo, moldadas em uma atmosfera de silêncio, ao articular na solidão dos indivíduos as vozes da memória, delineiam trilhas que conduzirão o leitor aos labirintos das consequências da "guerra" no interior humano.

\section{No silenciar das pedras as vozes da memória}

A memória reveste-se como uma das grandes marcas da obra antuniana. As narrativas afirmam que o inesquecivel sobrevive ao tempo, mesmo retido em cápsulas de silêncio cuja existência remeta ao espectro de mortos que não puderam ser sepultados. A fixação doentia no passado reflete, em todos os romances, o sintoma do ressentimento profundo nas personagens. A escrita, nessa perspectiva, configura-se como um signo de mortos que empreendem um duelo dicotômico, investindo suas estratégias de luta contra, ou a favor, do esquecimento. Nos romances antunianos há sempre a ação de peregrinar nas lembranças, pois ao posicionarem sua voz, em vez de se libertarem, as personagens se aprisionam em cárceres ainda mais densos. Destes calabouços de onde ecos são ouvidos, os textos são projetados e sublimados. As lembranças passam a ser verbalizadas, cenas 
traumáticas ressurgem dos escombros para, então, serem materializadas, nomeadas. A memória é o projeto de representação, tanto nas confissões quanto no fluxo de consciência das personagens, enquanto texto e máquina de escritura. Destarte a representação, para ter acesso à linguagem interior, necessita torturantemente, nos cárceres das limitações, passar pela ficção.

A obra Eu hei-de amar uma pedra aborda o impacto emocional do discurso, alimentado por fragmentos de imagens guardadas na memória. Ao mesmo tempo em que mobilizam as recordações pertinentes, possibilitam compreender que o romance configura-se como um corpo textual, constituído não apenas pelos convencionais componentes narrativos no relacionamento das personagens com o mundo referencial e com a configuração diegética conformadas pelo texto.

O título da obra em questão apresenta como sujeito da enunciação um "eu" desconhecido que, valendo-se de uma construção verbal conjugada no futuro, autopredestina-se a sentença de "amar uma pedra”. O texto de referência, do qual partiu a inspiração para o título do romance, sob a forma de uma citação literal, corresponde a um verso de um antigo cancioneiro português, cuja linha subsequente diz "beijar o teu coração". Na obra o foco principal da narrativa ocupa-se em expor os dramas advindos da angústia, solidão, frustrações individuais e convenções sociais, tendo como preocupação principal o registro de histórias anônimas e existenciais entrelaçadas às referências históricas. O cotidiano e os referidos bens imateriais das personagens são apresentados no discurso narrativo como uma outra maneira para se repensar as "verdades" históricas, utilizando-se, para tanto, de recursos como a relação entre a história e a memória e as figurações temporais.

A partir do exame de antigas fotografias, o romance produz uma sequência de quadros em que a reconstituição do passado, na perspectiva da memória, adquire contornos cujos traços vão se definindo em múltiplas perspectivas: tempos narrativos se sobrepõem e 
se mesclam, assim como as vozes dos personagens que, num sentido bakhtiniano, ondulam-se em vibrações polifônicas; a memória, ao ser estimulada pelas imagens cristalizada nos retratos, aciona o mecanismo da recordação, de modo que cores e desenhos, aparentemente destituídos de formas e significados, vão sendo projetados na tela do presente e, paulatinamente, restaurados com novos sentidos.

A característica polifonia do texto Eu hei-de amar uma pedra expressa uma relativa liberdade e independência das personagens em relação ao autor que, conforme Bakhtin enfatiza interessam "enquanto ponto de vista específico sobre o mundo e sobre si mesma" (BAKHTIN, 1981).

O texto é narrado por diversos personagens, os quais adquirem voz à proporção em que as linhas do romance seguem o seu fluir. No momento em que o leitor se apercebe acerca da mudança de voz narrativa, o fio condutor da história já está a desenrolar-se por outras paragens, filtrado pela percepção de outro personagem. Nesse contexto, a obra se configura mais como um inventário de impressões do que fatos ou acontecimentos que movam uma narrativa. O leitor, a partir dessa perspectiva, defronta-se com o desafio de organizar as informações subjacentes a tessitura textual, as quais exigem que sua percepção esteja atenta para captar as vibrações átonas, plangentes nas diversos micro-esferas de cada personagem que figura na obra.

Orientando-se pelo viés da perspectiva bakhtiniana, há de se considerar que, no plano polifônico, as explicações do romance são, diretamente, transferidas para a atmosfera da realidade. $O$ mérito dessa escrita consiste, assim, em subtrair qualquer esforço de unificação e paradoxo que a mesma contenha, ao primar pela multiplicidade e a qualidade contraditória como momento fundamental da construção textual e concepção artística. No primeiro capítulo de Eu hei-de amar uma pedra, intitulado como As fotografias, a escrita antuniana ocupa-se em representar lembranças, retidas no silêncio de imagens que $o$ estímulo fotográfico impediu que o tempo esvaecesse. 
Uma coleção fotográfica individual é, portanto, o objeto que provoca a aventura memorialista empreendida em Eu hei-de amar uma pedra, de modo que os contornos do passado vão sendo redefinidos em novas cores e, nesse processo de restauração das experiências vividas, motivos perdidos passam a adquirir projeções diferentes: segredos guardados são descortinados e personagens esquecidos adquirem a possibilidade de voltarem a atuar no palco das sensações que vão sendo vivenciadas.

A obra pode ser configurada como um romance que versa sobre o amor. A começar, assim, com um homem a revisitar as fotografias de sua vida e a deixar o fluxo da memória tomar conta. Em meio a essa sobreposição de imagens que o narrador recupera surge, desvanecida, a figura da mulher que um dia amara e, segundo as informações que dispunha, falecera em um sanatório em Coimbra.

A figura da antiga amada se presentifica na imagem de uma bailarina de corda. A consciência das ações passadas, que se projetam para o presente, ainda podem se configurar como uma memória. Todavia, essa perspectiva da memória está, em todas as circunstâncias, direcionada para a ação, situada no presente e tendo em consideração somente o futuro. O que está retido no passado são apenas os movimentos que, de modo inteligente, foram coordenados com o propósito de representar o seu esforço acumulado. A memória, nesse sentido, localiza esses esforços passados, não em imagens e lembranças que os recordam, "mas na ordem rigorosa e nos caráter sistemático com que os movimentos atuais se efetuam" (BERGSON, 1999. p. 89):

-Sou eu?

ao passo que a casca da tangerina e a garrafa de cerveja no banco perfeitas, decifrava-se o rótulo, a marca, se a bailarina de corda não tivesse falecido no sanatório em Coimbra exibia-lhe a névoa no dia em que me deixassem entrar, o portão aberto, o jardineiro a descer do escadote

(...)

-Lembras-te de mim?

o que eu passava, à espera de encontrá-la

(e se por acaso encontrava desviava a cabeça fingindo não ver) 
não no Beato, não na Calçada do Grilo, não na madre de Deus, para lá na direção do centro, deves ter demorado semanas a dar-te conta e dei conta que te deste conta dado que corria a escapar-me de ti, se a bailarina de corda não tivesse falecido no sanatório em Coimbra exibia-lhe a névoa

-Sou eu

com a mão esquerda no bolso tentando retirar a aliança com os outros dedos ${ }^{2}$

A passagem transcrita sugere a abertura de várias intersecções espaço-temporais, sobrepostas na articulação de vozes e evocações da memória, a propiciar que se liberte do claustro do esquecimento a sugestão inconclusa, e ainda vibrante, de um amor. Desprende-se, nesse ponto, um questionamento de ordem identitária, pois em um aparente não reconhecimento, uma das vozes está a interrogar-se "Sou eu?”. Na sequência, está expressa uma pungente marca de condicionalidade, ao se cogitar "se a bailarina de cordas não tivesse falecido...". A partir de então, as lembranças e fatos vão sendo organizados de tal maneira que as operações dialógicas, ao intercalar percepções sugeridas pelas imagens fotográficas com as oscilações das vozes das personagens, conduzem à derradeira elucidação do sujeito que se auto-identifica "Sou eu". A personagem busca, então, omitir o compromisso matrimonial selado pela aliança que, disfarçadamente, ocupa-se em tentar esconder. Bakhtin considera que no plano discursivo da autoconsciência já não é mais possivel concluir e fechar a personagem, bem como edificar-lhe uma imagem integral, que ofereça uma resposta artística a questão "quem ela é" (BAKHTIN, p. 40). Assim, como a transcrição supracitada ilustra, o leitor não vê nitidamente quem os personagens são, mas a maneira como eles adquirem consciência de si mesmos, ao acionar os recursos subjacentes à memória dos fatos vividos condensados nas imagens retidas fotograficamente.

- Olhe

2 ANTUNES, António Lobo. Eu hei-de amar uma pedra. Rio de Janeiro: Objetiva, 2007. p. 96-97. 
a alongares-te no retrato, cerimoniosa, atenta, comigo a calcular

- Mesmo que tire a aliança fica a marca estou feito

mantendo todo o tempo a mão no bolso, impedindo-te de me devolver a fotografia

- É para ti

não, nessa época

- É para si

consciente dos pinheiros e do arquipélago de cães que daqui a pouco à noite, antes que eu

- Posso voltar para a semana menina?

Aqui, pode-se constar que a memória, por vincular o passado ao presente, é responsável por produzir uma dupla operação. A primeira ocupa-se em abolir o tempo, considerando a permanência memorável daquilo que transcorreu; a segunda, busca representá-lo, pois a conjunção do "antes" com o "agora" possibilita que se vislumbre uma transformação. O imutável é o que não tem tempo. A memória entrelaça os fios da atualidade com o passado, de modo que é possível recorrer-se a ela com o propósito de se rastrear a origem das coisas, mas também para elucidar alguma perspectiva futura. Pode-se, portanto, perceber que o casual fragmento de tempo fotografado congrega em si o potencial de conter o antes e depois.

Os elementos que o silêncio reteve em sua resina no transcorrer de tantos anos, os quais permaneceram abrigados na melodia de recordações entoadas em surdina e na cumplicidade neutra de fotografias são, a partir do reencontro de ambas as personagens, gradativamente restaurados. No primeiro plano instauram-se as ações operadas pela lembrança, seguidas pela sublime veleidade do reconhecer-se, identificar-se e retomar o fio interrompido de uma história para a qual a plenitude, novamente, abre-se como um improvável horizonte.

\section{"O teu silêncio que me embala é a ideia de naufragar": (im)propriedades dos seres e das coisas}

O romance Boa tarde às coisas aqui embaixo, a seguir o modelo tradicional das obras antunianas, caracteriza-se como uma narrativa 
na qual se interpolam histórias de homens e de mulheres que, mesmo vivendo tempos e espaços específicos, em diversas situações "nos labirintos de tempos e vozes em que os textos de António Lobo Antunes nos enredam" (SEIXO, 2002, p. 10), acabam por se defrontar, de forma constante, com os espectros de passados que se reestruturam em cada situação presente.

Um aspecto significativo em Boa tarde às coisas aqui embaixo reside no fato de que a história de determinadas personagens, ao ser narrada em primeira pessoa, acaba por ser figurada pelo próprio sujeito que, de modo reflexivo, se representa por certo objeto cujo ato de recordar se encontra marcado pelos seus sons tipificados. Em consonância com Seixo:

qualquer tempo experienciado pelo narrador ou por alguma personagem, é sempre, afinal a duração atualizada dos vários planos da memória, que confluem numa mente singular e a remetem ao espaço que a enunciação indicia" (2002,p.492).

Neste enquadramento de texto está situada a obra, ao apresentar, sob uma perspectiva fragmentária, o indivíduo português deslocado na atmosfera pós-colonial e na sua própria atmosfera interior. A escassez de referências, a verdade que se relativiza, a oscilação entre mundos teoricamente possíveis dos relatos envolvem-se em um clima de tensão, e, por vezes, de silêncio nesse texto.

As vozes que se sobressaem no contexto narrativo expressam a flagelação humana em suas especificidades interiores. Nessa mesma perspectiva, o texto representa um universo de degradação e ruínas de ordem moral de dois grandes sistemas fragilizados: o império colonial português e a realidade angolana pós-colonialismo. Boa tarde às coisas aqui embaixo conduz aos labirintos das consequências da guerra para o ser humano. Assim, a exposição da conturbação interior do homem se visualiza a partir da fragmentação, não somente da estrutura estilística, mas também por meio da fragmentada estrutura do pensamento, do raciocínio das "vozes" que, por alguns momentos se manifestam, por outros se calam no romance. 
- Outra vez

ordenei à minha esposa, pasmada, em silêncio

- Cala-te

dado que o silêncio me rebentava aos ouvidos fazendo os possiveis para me distrair dos carvalhos enquanto cortava eu o pão e o pão a sangrar, depois do falecimento do meu pai houve um silêncio desse gênero nas paredes, na cómoda, para emudecer o silêncio estanquei no meio da sala, desafiei a cómoda e as paredes enrugando-lhes o queixo e comecei a cantar, a minha esposa extraiu dos seus lutos no medo das indignações do rés-do-chão

devido ao sol nos carvalhos metade das folhas na luz e metade nas sombras ${ }^{3}$

Além da abordagem relativizada das calamidades humanas, as quais são retratadas por meio das frustrações portuguesas, Boa tarde às coisas aqui embaixo evidencia uma das maiores problemáticas de Portugal, que é o continente africano. Este se projeta como cenário de antigos conflitos entre portugueses e os seus habitantes, como o desentendimento ocorrido no século XVII, em Angola, época do domínio da Rainha Nzinga, que chegou a realizar alianças com os holandeses para tentar expulsar os portugueses do seu território. Não é possível, pois, classificar o romance como tendo um caráter sociológico, uma vez que Lobo Antunes não realiza um retrato da guerra colonial e dos conflitos pós-coloniais, mas se utiliza dos episódios da história para explorar a conturbação da alma humana.

Bakhtin vê a linguagem como um fenômeno social e histórico, que visa à comunicação entre os indivíduos. Assim, para o filósofo, a palavra possui natureza dialógica. As palavras são usadas a partir de um efeito de sentido que o sujeito pretende alcançar no momento da enunciação, ou seja, no momento do uso concreto da língua.

3 ANTUNES, António Lobo. Boa tarde às coisas aqui embaixo. Rio de Janeiro: Objetiva, 2007. Segundo Livro - Capítulo Primeiro, p. 211. 
Partindo da concepção de que a personagem não coincide consigo mesma, atinge-se ao que Bakhtin chama de monólogo dialogado, ou microdiálogo, no qual a personagem, ao fazer uma reflexão, dialoga com o discurso de outrem. Isto se fundamenta em outra ideia importante, a de que "a tarefa polifônica é incompativel com uma só ideia" (BAKHTIN, p. 65). Assim, tais ideias não são simplesmente representadas pelas personagens, mas afirmadas por elas.

Será que remendo isso com palavras ou falo do que aconteceu de facto, não aqui, em Lisboa e em Luanda cinco anos atrás? Cinco anos é muito tempo

eu sei

mas às vezes, ao acabar o dia, nesta fazenda de que não me ocupo

(ninguém se ocupa, ocupam-se os pássaros que vão engolindo sem pressa, a fitarem-me de lado, o que sobeja do girassol e do algodão)

(fuga para onde se não se foge de Angola, só demasiado tarde compreendi que não se foge de Angola, a Europa demasiado longe e depois a indiferença, o cansaço, a idade porque nos gastamos tão depressa em África, um encolher de ombros, uma resignação de

- E depois?) $)^{4}$

O posicionamento português certifica que as histórias de Portugal e de Angola estão interligadas na narrativa antuniana e na memória, bem como na memória de cada português e de cada angolano. A escrita e a memória fragmentadas do romance atingem o cerne dos problemas, não apenas de portugueses e africanos, mas de qualquer agente da realidade, uma vez que a escrita de Lobo Antunes envolve as "vozes" portuguesas e angolanas que se entrelaçam no discurso fictício da vida.

4 ANTUNES, António Lobo. Boa tarde às coisas aqui embaixo. Rio de Janeiro: Objetiva, 2007. Primeiro Livro - Capitulo Primeiro, p. 27. 
Em Boa tarde às coisas aqui em baixo o leitor é remetido ao encontro do africano com o angolano; do português com o colonizador; do humano com a sua problemática interior. O que se encontra ou reencontra nesta narrativa é a fragmentada gênese humana retratada pela imagem da escrita impetuosa e sedutora de António Lobo Antunes. Este romance evoca em cada memória e voz que o lê, as marcas peculiares, singulares do homem lançado num sistema pós-moderno, como os touros que são remetidos à revelia, e, sem piedade em uma arena de conturbadas lutas.

\section{"Silêncio, que quer dizer": outras, últimas, palavras}

A sucessão de quadros narrativos suspensos nas páginas de $E u$ hei-de amar uma pedra e Boa tarde às coisas aqui embaixo configuram a polifonia de vozes inquietas que possibilitam a abertura do caminho para o entendimento do impacto emocional do discurso, alimentado por fragmentos de imagens guardadas na memória. Estas, ao mesmo tempo em que mobilizam as recordações pertinentes, se tornam o motor da patemização. E é para este vínculo de cumplicidade que o texto convida o leitor: convida-o a partilhar o recordatório de que não só se tem em comum este ou aquele resíduo de conhecimento, mas todo um mundo ou forma de viver comum; convida-o a entrar num mundo de crenças e de valores conjuntamente contemplados. O convite não é pontual nem neutro. Desencadeia um efeito de eco que reverbera pelos perfis das memórias de cada um, conduzindo o leitor por sugestões tácitas.

Do mesmo modo, a necessidade da existência do outro para o crescimento do ser humano, para tornar sua visão do mundo mais complexa e mais rica, se reflete na literatura. Ela se tornará, portanto, mais profunda e complexa, obterá mais possibilidades de interpretação, se levar em consideração a necessidade da outra voz. A valer-se das palavras de Bakhtin "é somente quando contrai relações dialógicas essenciais com as ideias dos outros é que a ideia começa a ter vida, isto 
é, a tornar-se, desenvolver-se, a encontrar e renovar sua expressão verbal e gerar novas ideias" (BAKHTIN,p. 73).

São muitos os elementos que contribuem para a construção desse "intercâmbio discursivo", essa "tessitura polifônica na qual confluem, se entrecruzam, se metamorfoseiam, se corroboram ou se contestam outros textos, outras vozes e outras consciências" (AGUIAR E SILVA, 1983), que é o texto de todos os grandes escritores que acreditam na diversidade e na democracia.

Essa alternativa parece criar um movimento produtivo, uma vez que a memória acionada é usada como alimento e arquivo de consulta. Esse processo atua como uma espécie de "baú de lembranças" (BACHELARD,p.112), tornando possivel o reviver de sensações necessárias à compreensão do crescimento e das transformações do mundo. Neste caso, o passado, parte importante da constituição dos personagens, é usado de forma positiva, produtiva, como matéria prima útil ao constante desenvolvimento.

Ao falar dos espaços passados e rever os seus respectivos ambientes, Lobo Antunes efetiva em Boa tarde às coisas aqui embaixo e Eu hei-de amar uma pedra uma leitura da realidade, oferecendo ao leitor um panorama íntimo, que funcionará como um espelho, vivenciado por este de diferentes maneiras. Esse procedimento é operado pelo autor, quando retorna ao mesmo ambiente do passado através de vários olhares diferentes. Esta sucessão de leituras abre inúmeras possibilidades de aproveitamento no acervo pessoal do leitor, estimulando-o a acionar seus espaços de memória. Uma mesma imagem torna o leitor capaz de perceber os espaços-tempos, ora vividos como experimentados e explorados, ora como perdidos e desperdiçados.

\section{Referências Bibliográficas:}

AGUIAR E SILVA, Vitor Manuel. Teoria da Literatura. 5. ed. Coimbra: Almedina, 1983. 
ANTUNES, António Lobo. Boa tarde às coisas aqui embaixo. Rio de Janeiro: Objetiva, 2007.

ANTUNES, António Lobo. Eu hei-de amar uma pedra. Rio de Janeiro: Objetiva, 2007.

BACHELARD, Gaston. A poética do espaço. São Paulo: Martins Fontes, 2000.

BAKHTIN, Mikhail. Problemas da poética de Dostoiéuski. Rio de Janeiro: Forense-Universitária, 1981.

BARTHES, Roland. Inéditos, I: teoria. São Paulo: Martins Fontes, 2004. BERGSON, Henri. Matéria e memória. Ensaio sobre a relação do corpo com o espírito. São Paulo: Martins Fontes, 1999.

SEIXO, Maria Alzira. Os romances de António Lobo Antunes. Lisboa: Dom Quixote, 2002. 